\title{
Cervical anaerobic vertebral osteomyelitis following surgical tracheotomy: a case report
}

\author{
Romaric Larcher ${ }^{*^{*}}$ D , Camille Maury ${ }^{2}$, Jonathan Charbit ${ }^{2}$, Helene Jean-Pierre ${ }^{3}$, Vincent Le Moing ${ }^{4}$, \\ Kada Klouche ${ }^{1}$ and Xavier Capdevila ${ }^{2,5}$
}

\begin{abstract}
Background: We report a rare case of anaerobic vertebral osteomyelitis associated with surgical tracheotomy which has never been reported to the best of our knowledge.

Case presentation: A healthy 39-year-old man was admitted to intensive care for a severe brain trauma injury where a surgical tracheotomy was performed. He was discharged to a rehabilitation centre after 54 days hospital stay. During rehabilitation, he developed progressive and febrile tetraplegia associated with cervical pain, requiring an intensive care readmission. A polymicrobial anaerobic bloodstream infection was revealed and magnetic resonance imaging diagnosed cervical vertebral osteomyelitis. Both the type of anaerobic micro-organisms found and the timing of the symptoms strongly suggest that the surgical tracheotomy was responsible for this rare case of cervical vertebral osteomyelitis. The patient was successfully treated by a prolonged antimicrobial therapy and by surgical laminectomy.
\end{abstract}

Conclusions: Tracheotomy may generate anaerobic bacteraemia and related osteomyelitis in the specific setting of severe trauma patients. Clinicians should consider anaerobic vertebral osteomyelitis when they are confronted with a febrile tetraplegia after tracheotomy.

Keywords: Anaerobic, Anaerobes, Cervical vertebral osteomyelitis, Tracheotomy, Tracheostomy, Trauma patient, case report

\section{Background}

Bacteraemia following tracheotomy occurs in approximately $20 \%$ of procedures, but septic metastasis remains rare [1]. Despite the advent of molecular identification and matrix-assisted laser desorption ionization time-of-flight (MALDI-TOF) mass spectrometry, anaerobic bacteraemia, frequently polymicrobial, and related bone and joint infections are yet underestimated [2]. We report herein a case of anaerobic cervical vertebral osteomyelitis as a delayed complication of surgical tracheotomy.

\footnotetext{
* Correspondence: r-larcher@chu-montpellier.fr

${ }^{1}$ Intensive Care Medicine Department, Lapeyronie Hospital, Montpellier, France

Full list of author information is available at the end of the article
}

\section{Case presentation}

A healthy 39-year-old man was admitted to the intensive care unit (ICU) for a severe trauma brain injury and a moderate thoracic trauma caused by a motorcycle accident. After initial computed tomography (CT-scan), the patient had immediate craniectomy and hematoma evacuation surgery with an antibiotic prophylaxis by cefazolin. An Enterobacter aerogenes ventilator associated pneumonia was diagnosed on day 14, and treated by cefepim for 8 days. After 30 days in ICU, neurological examination showed a minimally conscious state and right lower limb monoplegia. A percutaneous endoscopic gastrostomy (PEG) was therefore positioned on day 31 with an antibiotic prophylaxis by amoxicillin/clavulanate $(2 \mathrm{~g})$. A surgical tracheotomy was also performed on day 33, as we use to do in our trauma ICU. Antibiotic prophylaxis was not administered during this

(c) The Author(s). 2019 Open Access This article is distributed under the terms of the Creative Commons Attribution 4.0 International License (http://creativecommons.org/licenses/by/4.0/), which permits unrestricted use, distribution, and reproduction in any medium, provided you give appropriate credit to the original author(s) and the source, provide a link to the Creative Commons license, and indicate if changes were made. The Creative Commons Public Domain Dedication waiver (http://creativecommons.org/publicdomain/zero/1.0/) applies to the data made available in this article, unless otherwise stated. 
procedure. There was no local complication or fever immediately around the surgical tracheostomy. The patient was weaned on day 40. On ICU discharge (day 54), neurological examination was unchanged. The patient was thereafter transferred to a rehabilitation centre.

During the second week of rehabilitation stay, fever, purulent pulmonary secretions, dyspnoea and cervical pain with progressive tetraplegia appeared. The patient was rapidly readmitted to the ICU where a broadspectrum antimicrobial therapy including piperacillin/ tazobactam ( $4.5 \mathrm{~g}$ four times a day), amikacin $(30 \mathrm{mg} / \mathrm{kg}$ ) and linezolid (600 mg twice a day) was initiated after multiple bacteriological samples. CT-scan and Magnetic Resonance Imaging (MRI) revealed C6-C7 vertebral osteomyelitis associated with a C2-T3 epidural abscess, a right C6-C7 paravertebral abscess and a cervical myelitis (Fig. 1). Among bacteriologic assessment, Parvimonas micra, Dialister pneumocintes and Veillonella parvela were isolated in three blood cultures. The anaerobes were susceptible to amoxicillin/clavulanate, imipenem and metronidazole, but resistant to clindamycin. The antimicrobial therapy was thus targeted to metronidazole $(500 \mathrm{mg}$ every $8 \mathrm{~h}$ ) and amoxicillin/clavulanate (2 $\mathrm{g}$ every $4 \mathrm{~h}$ ). Cultures of arterial and central venous catheters were negative. Complementary investigations by oral examination, nasofibroscopy, facial and cervical CT-scan, and transoesophageal echocardiography did not reveal any infection source. Two weeks later, cervical vertebrae laminectomy was performed because of persistent fever and tetraplegia. Surgical vertebral biopsies cultures performed under antimicrobial therapy were negative. After laminectomy and a total of 5 weeks of antimicrobial therapy, the patient was apyretic and recovered mobility of the four limbs. He was discharged to the rehabilitation centre after 44 days, treated by amoxicillin/clavulanate and rifampin
(900 mg a day) according to susceptibility test. Treatment was well tolerated.

\section{Discussion and conclusions}

Bacteraemia following tracheotomy may occur in about $8-9 \%$ of case [1]. However septic metastasis remains uncommon. We report a case of cervical anaerobic vertebral osteomyelitis which was probably secondary to a surgical tracheotomy procedure. Such a deleterious effect of tracheotomy has never been reported at the best of our knowledge.

Vertebral osteomyelitis whore diagnosis was based on fever, tetraplegia, elevated CRP, and confirmed by bloodstream infection contemporaneous of typical MRI, according to international Guidelines [3]. The fact that surgical vertebral biopsies were negative did not rule out this diagnosis since broad spectrum antimicrobial treatment was already administered.

Our main concern in this case was the infection source. Micro-organisms found and timing of clinical findings strongly suggest that the most likely underlying cause of this vertebral osteomyelitis was the surgical tracheotomy. Namely, the presence in blood cultures of D. pneumosintes, which is a commensal organism exclusively found in the oral cavity, points towards an oro-pharyngeal source [4]. In addition, sepsis and neurologic symptoms occurred 30 days after this procedure, which is consistent with usual timing of vertebral osteomyelitis, a diagnosis often delayed by several months [5]. Alternative sources of infection appear less likely. Indeed, craniectomy was performed with cefazolin prophylaxis, more than 60 days before bacteraemia, and no local sign of infection was found on CT-scan or around the surgical site. PEG was performed without complication under amoxicillin/clavulanate prophylaxis. A haematogenous spread mechanism

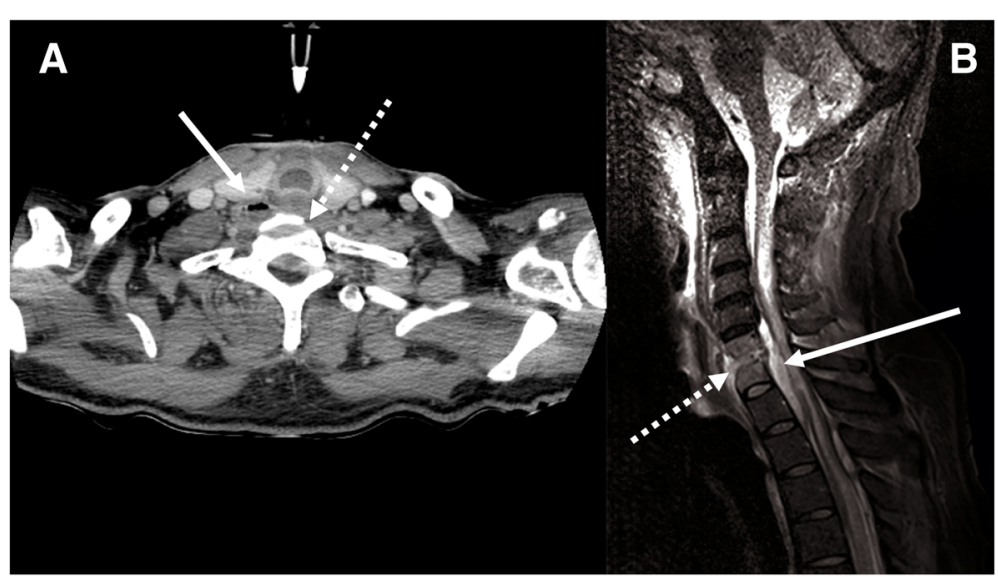

Fig. 1 a Cervical computed tomography scanner: erosion of C6 vertebral body endplate (white dotted arrow) associated with epidural and right paravertebral hydro-aeric collections (white arrow). b Cervical and medullar magnetic resonance imaging: STIR hypersignal of disc with irregularity and erosion of C6-C7 vertebral body endplates (white dotted arrow), and epidural collections (white arrow) 
seems more probable than a local septic extension owning that: no direct inoculation or contamination from adjacent soft tissue was evidenced on various investigations by appropriate specialists.

No morbid condition was recorded in the patients' medical history and glycaemic control was optimized under insulin therapy, but tissue injury following trauma may result in immunoparesis leading to an increased risk of infection [6].

In conclusion, we report a case of cervical vertebral osteomyelitis which appears to be an exceptional complication of surgical tracheotomy. Our observation remains uncommon but may inform clinicians to consider it when progressive febrile tetraplegia after a tracheotomy occurs.

\section{Abbreviations}

CT-scan: Computed tomography scanner; ICU: Intensive care unit; MALDITOF: Molecular identification and matrix-assisted laser desorption ionization time-of-flight; MRI: Magnetic resonance imaging; PEG: Percutaneous endoscopic gastrostomy

\section{Acknowledgments}

Dr. Yann Thouvenin for reviewing of CT-scans and MRI, and selecting relevant images. Dr. Julie Carr for reviewing this manuscript.

\section{Authors' contributions}

$\mathrm{RL}$ and $\mathrm{CM}$ contributed to study design, literature search, data collection, analysis and interpretation, and writing. JC contributed to data analysis and interpretation, writing and critical revision. HJP and VLM contributed to data analysis and interpretation, and critical revision. KK and XC contributed to study design and critical revision. All authors read and approved the final manuscript.

\section{Funding}

None.

\section{Availability of data and materials}

Data sharing is not applicable to this article as no datasets were generated or analysed during the current study.

\section{Ethics approval and consent to participate}

Patient informed consent and local institutional review board approbation (2018 IRB-MTP_07-11) were obtained.

\section{Consent for publication}

A written consent for publication has been obtained from the patient.

\section{Competing interests}

The authors declare that they have no competing interests.

\section{Author details}

'Intensive Care Medicine Department, Lapeyronie Hospital, Montpellier, France. ${ }^{2}$ Intensive Care Unit, Anaesthesiology and Intensive Care Department, Lapeyronie Hospital, Montpellier University Hospital, Montpellier, France. ${ }^{3}$ Bacteriology Department, Arnaud de Villeneuve Hospital, Montpellier University Hospital, Montpellier, France. ${ }^{4}$ Tropical and Infectious Diseases Department, Saint Eloi Hospital, Montpellier University Hospital, Montpellier, France. ${ }^{5}$ INM, University Montpellier, INSERM, Montpellier, France.

Received: 19 October 2018 Accepted: 16 July 2019

Published online: 22 July 2019

\section{References}

1. Antonelli M, Michetti V, Di Palma A, Conti G, Pennisi MA, Arcangeli A, et al. Percutaneous translaryngeal versus surgical tracheostomy: a randomized trial with 1-yr double-blind follow-up. Crit Care Med. 2005;33:1015-20.
2. Walter $G$, Vernier $M$, Pinelli $P O$, Million $M$, Coulange $M$, Seng $P$, et al. Bone and joint infections due to anaerobic bacteria: an analysis of 61 cases and review of the literature. Eur J Clin Microbiol Infect Dis Off Publ Eur Soc Clin Microbiol. 2014;33:1355-64.

3. Berbari EF, Kanj SS, Kowalski TJ, Darouiche RO, Widmer AF, Schmitt SK, et al. Executive summary: 2015 Infectious Diseases Society of America (IDSA) clinical practice guidelines for the diagnosis and treatment of native vertebral osteomyelitis in adults. Clin Infect Dis. 2015;61:859-63.

4. Kogure M, Suzuki H, Ishiguro S, Ueda A, Nakahara T, Tamai K, et al. Dialister pneumosintes bacteremia caused by dental caries and sinusitis. Intern Med. 2015;54:663-7.

5. Gupta A, Kowalski TJ, Osmon DR, Enzler M, Steckelberg JM, Huddleston PM, et al. Long-term outcome of pyogenic vertebral osteomyelitis: a cohort study of 260 patients. Open Forum Infect Dis. 2014;1:ofu107.

6. Lord JM, Midwinter MJ, Chen Y-F, Belli A, Brohi K, Kovacs EJ, et al. The systemic immune response to trauma: an overview of pathophysiology and treatment. Lancet. 2014;384:1455-65.

\section{Publisher's Note}

Springer Nature remains neutral with regard to jurisdictional claims in published maps and institutional affiliations.

Ready to submit your research? Choose BMC and benefit from:

- fast, convenient online submission

- thorough peer review by experienced researchers in your field

- rapid publication on acceptance

- support for research data, including large and complex data types

- gold Open Access which fosters wider collaboration and increased citations

- maximum visibility for your research: over $100 \mathrm{M}$ website views per year

At BMC, research is always in progress.

Learn more biomedcentral.com/submissions 